GRASAS Y ACEITES 72 (3)

July-September 2021, e420

ISSN-L: 0017-3495

https://doi.org/10.3989/gya.0325201

\title{
Thermal and chemical characterization of fractions from Syagrus romanzoffiana kernel oil
}

\author{
๑T.S. Tavares ${ }^{\mathrm{a}}$, $₫$ K.T. Magalhães ${ }^{\mathrm{a}}, \oplus$ N.D. Lorenzo ${ }^{\mathrm{a}}$ and $₫$ C.A. Nunes $\mathrm{s}^{\mathrm{b}, \bowtie}$ \\ ${ }^{a}$ Department of Chemistry, Federal University of Lavras, University Campus, Post Office Box 3037, 37200-000 Lavras, Minas Gerais, Brazil \\ ${ }^{b}$ Department of Food Science, Federal University of Lavras, University Campus, Post Office Box 3037, 37200-000 Lavras, Minas Gerais, Brazil \\ Corresponding author: cleiton.nunes@ufla.br
}

Submitted: 02 March 2020; Accepted: 29 June 2020; Published online:15 September 2021

\begin{abstract}
SUMMARY: The Jerivá (Syagrus romanzoffiana) kernel oil (JKO) has a pleasant coconut-like smell, with about 33\% lauric acid and $28 \%$ oleic acid. The oil also contains bioactive compounds, such as phenolics, carotenoids, and tocopherols. JKO has a solid consistency at low temperatures, but has a low melting point and low solid content at room temperature. Thus, this work aimed to evaluate the thermal properties related to crystallization and fusion, as well as the chemical and oxidative characteristics of JKO fractions, olein and stearin, obtained from dry and solvent fractionation. In general, stearins had higher crystallization and melting temperatures, and higher solid fat content, unlike oleins, which may be associated with the concentration of high melting triglycerides in the stearins. No statistically significant difference was found for fatty acid profile or oxidative stability of the fractions. The type of fractionation influenced the chemical and thermal properties of JKO fractions. The solvent process promoted the most relevant differentiation of fractions. An olein was obtained with $7 \%$ less solid fat at $25{ }^{\circ} \mathrm{C}$ which remained visually liquid at $2{ }^{\circ} \mathrm{C}$ below the oil, as well as a stearin with $17 \%$ more solid fat at $25{ }^{\circ} \mathrm{C}$ which remained visually solid at $3{ }^{\circ} \mathrm{C}$ above the oil.
\end{abstract}

KEYWORDS: Crystallization; Fractionation; Melting; Olein; Stearin

RESUMEN: Caracterización térmica y química de fracciones de aceite de semilla de Syagrus romanzoffiana. El aceite de semilla de Jerivá (Syagrus romanzoffiana) (ASJ) tiene un agradable olor a coco, con aproximadamente un $33 \%$ de ácido láurico y un $28 \%$ de ácido oleico. Este aceite también contiene compuestos bioactivos, como fenólicos, carotenoides y tocoferoles. El ASJ tiene una consistencia sólida a baja temperatura, pero tiene un punto de fusión bajo y un contenido de sólidos bajo a temperatura ambiente. Este trabajo tuvo como objetivo evaluar las propiedades térmicas relacionadas con la cristalización y fusión, así como las características químicas y oxidativas de las fracciones de ASJ, oleína y estearina, obtenidas mediante fraccionamiento en seco y con solvente. En general, las estearinas tuvieron temperaturas de cristalización y fusión más altas y un mayor contenido de grasa sólida, a diferencia de las oleínas, esto puede estar asociado con la concentración de triglicéridos de alto punto de fusión en las estearinas. No se encontraron diferencias estadísticamente significativas para el perfil de ácidos grasos ni en la estabilidad oxidativa de las fracciones. El tipo de fraccionamiento influyó en las propiedades químicas y térmicas de las fracciones de ASJK. El proceso mediante solvente favoreció la diferenciación de fracciones más relevantes. Se obtuvo una oleína con $7 \%$ menos de grasa sólida a $25{ }^{\circ} \mathrm{C}$ que permaneció visualmente líquida a $2{ }^{\circ} \mathrm{C}$ por debajo del aceite, así como una estearina con $17 \%$ más de grasa sólida a $25^{\circ} \mathrm{C}$ y que permaneció visualmente sólida a $3{ }^{\circ} \mathrm{C}$ por encima del aceite.

PALABRAS CLAVE: Cristalización; Estearina; Fusión; Fraccionamiento; Oleina

Citation/Cómo citar este artículo: Tavares TS, Magalhães KT, Lorenzo ND, Nunes CA. 2021. Thermal and chemical characterization of fractions from Syagrus romanzoffiana kernel oil. Grasas Aceites 72 (3), e420. https://doi.org/10.3989/gya.0325201

Copyright: (C2021 CSIC. This is an open-access article distributed under the terms of the Creative Commons Attribution 4.0 International (CC BY 4.0) License. 


\section{INTRODUCTION}

Lauric oils are obtained from various palm species and are characterized mainly by high contents in lauric acid (C12:0) and small amounts of other medium and short-chain fatty acids. Lauric oils can be found mainly in coconut and palm kernels, Jarivá, and Macaúba, which have a solid consistency at low room temperatures but still melt below $30^{\circ} \mathrm{C}$ (Coimbra and Jorge, 2011; Gunstone, 2010). Therefore, these natural fats have a short melting range, which makes them suitable for the manufacture of a variety of fatty foods. In this respect, the low melting points and the low solid contents at room temperature are favorable for the production of some products, such as confectionery coatings and couvertures; although it is a drawback that can be alleviated by the fractional crystallization and separation of harder and softer fractions (Gunstone, 2010; Magalhães et al., 2020b; Rossell, 1985). In this sense, fractional crystallization, or simply fractionation, refers to a separation process in which fatty material is crystallized at a suitable temperature, after which a low melting phase (olein) is separated from a high melting phase (stearin) (Kellens et al., 2007; Sonwai et al., 2017). Nowadays, where trans fatty acids in food are questioned, fractionation oil modification stands out as an alternative for the industry because it is a physical process that does not promote changes in fat at the molecular level (Kellens et al., 2007; Magalhães et al., 2020b; Sonwai et al., 2017).

Lauric oils are widely modified by fractionation. Olein and stearin are obtained in this process in order to increase the applicability of the oils in different food processes. They are used in the food industry to produce spreads, specialty fats, ice cream, chocolate, and others, where most of them are specially derived from palm kernel oil. In addition, the increasing use of cocoa butter substitutes by the chocolate industry drives a growing demand for lauric oils (Calliauw et al., 2007; Chaleepa et al., 2010; Kellens et al., 2007; Magalhães et al., 2020b; Rossell 1985; Sonwai et al., 2017). Therefore, there is still room to explore other lauric oils, as well as their fractions, to obtain products with distinct characteristics from or equivalent to those derived from palm or coconut oil.

In this context, the Syagrus romanzoffiana palm is an interesting alternative resource in the production of lauric oil. This plant, commonly known as Jerivá, queen palm or coconut palm, is a native palm tree from South America and was introduced around the world as a popular ornamental garden tree used in urban landscaping (Pittenger et al., 2009). The Jerivá palm fruit is an oval drupe, yellowish or orange, with a rigid endocarp involving an almond with about $50 \%$ oil. The almond (kernel) oil has a pleasant coconut-like smell, with about $33 \%$ lauric acid and $28 \%$ oleic acid. The oil also contains bioactive compounds, such as phenolics, carotenoids, and tocopherols (Coimbra and Jorge, 2011; Coimbra and Jorge, 2012; Pierezan et al., 2015; Magalhães et al., 2020b). Jerivá kernel oil has interesting characteristics for biofuel production, such as low acidity, a high oxidative stability and transesterification reaction with an ester conversion rate above the minimum percentage required (Falasca et al., 2012; Moreira et al., 2013), but also has potential for human consumption (Lescano et al., 2018; Magalhães et al., 2020a). Nevertheless, research aiming to explore food applications of $\mathrm{JKO}$ is scarce.

Thus, this work aimed to evaluate the thermal properties related to crystallization and fusion, as well as the chemical and oxidative characteristics of JKO fractions obtained from dry and solvent fractionation. Possible changes in the fatty acid profile and oxidative stability of the fractions were evaluated by gas chromatography and Rancimat, respectively. Differential Scanning Calorimetry was used to assess the solid fat content, and the crystallization and melting behavior of the fractions. Changes in the physical state were determined by visual inspection.

\section{MATERIALS AND METHODS}

\subsection{Oil extraction}

The jerivá fruits (Figure 1) were collected from the south-east region of Brazil (Lavras, Minas Gerais state) directly from the ground in the mature stage, broken in a hydraulic press (MPH-15, Marcon) and the kernels were manually separated. The JKO was obtained using an expeller press (Home Up Yoda), with an oil yield of $42.6 \%$, and centrifuged for 5 minutes at $4000 \mathrm{rpm}$ (relative centrifugal force of $2150 \mathrm{~g}$ ) to remove fine particles. Figure 1 illustrates the treatment process of treatment and characterization of the samples. 


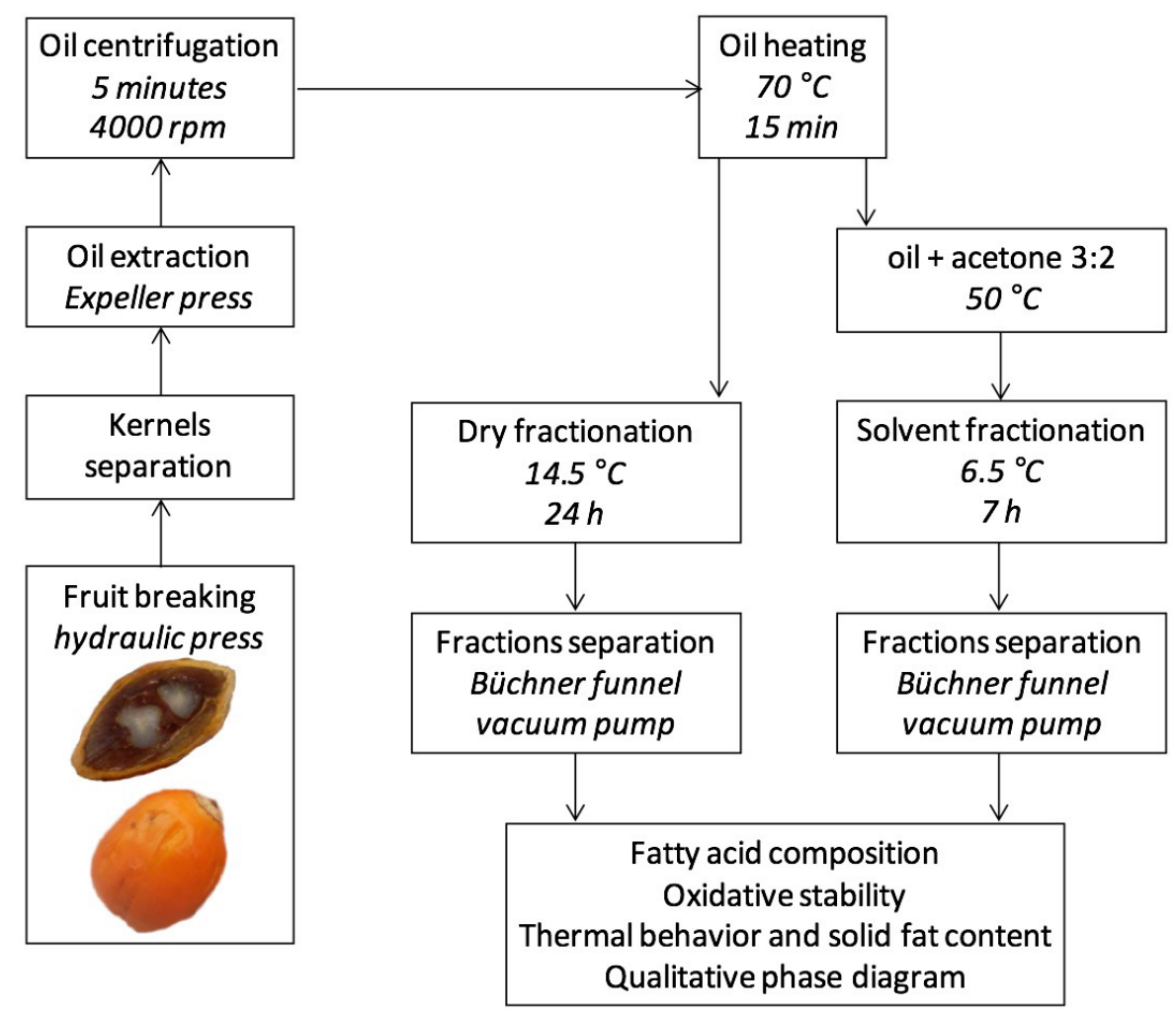

FIGURE 1. Process of extraction, fractionation and characterization of Jerivá kernel oil (JKO) and its fractions.

\subsection{Fractionation}

\subsubsection{Dry fractionation}

JKO $(30 \mathrm{~g})$ was heated in a water bath $(\mathrm{HH}-$ S3-Warmnest) at $70{ }^{\circ} \mathrm{C}$ for $15 \mathrm{~min}$ to remove any previous structure. The oil was cooled in BOD (T-34-THELGA) at $14.5^{\circ} \mathrm{C}$ for $24 \mathrm{~h}$. The fractions were separated by centrifugation (K14-4000-Kasvi) for 2 minutes at $4000 \mathrm{rpm}$. Olein and stearin were weighed to evaluate yield.

\subsubsection{Solvent fractionation}

The fractionation was carried out in a 100 $\mathrm{mL}$ jacketed glass reactor, connected to an ultratermostatic bath (Q214M-Quimis) with water circulation. The fractionation conditions established by Sonwai (2017) for coconut oil were used, with modifications defined through previous tests. Tests were carried out at different temperatures between 10 and $6{ }^{\circ} \mathrm{C}$ using a mass of $30 \mathrm{~g}$ of oil previously heated at $70^{\circ} \mathrm{C}$ in a water bath (HH-S3-Warmnest) for 15 minutes and then cooled to $50^{\circ} \mathrm{C}$ before being mixed with $20 \mathrm{~mL}$ of hot acetone $\left(50^{\circ} \mathrm{C}\right)$.
The temperature at which the crystals formed in significant amounts and remained stable was at $6.5^{\circ} \mathrm{C}$, in which two fractions were carried out: one for 5 hours with agitation at $20 \mathrm{rpm}$ and another for 7 hours without agitation. After the crystals were formed, the fractions were separated by sieving ( 72 mesh) and the acetone was evaporated. Oleins and stearins were weighed to evaluate yield.

\subsection{Fatty acid composition}

A fatty acid composition analysis was performed according to the AOCS Ce 2-66 method (AOCS, 1993). Samples were transesterified in methyl esters with potassium hydroxide in methanol and n-hexane. All reagents and solvents (analytical grade) were from Vetec. The methyl esters were analyzed by gas chromatography (GC-2010 - Shimadzu) equipped with a flame ionization detector and an SPTM-2330 capillary column $(30 \mathrm{~m} \times 0.25 \mathrm{~mm} \times 0.20 \mu \mathrm{m})$. Chromatographic conditions were split ratio 1:100, initial column temperature $140{ }^{\circ} \mathrm{C}$, heating from 140 ${ }^{\circ} \mathrm{C}$ to $250{ }^{\circ} \mathrm{C}$ for $3 \mathrm{~min}$ at a rate of $5^{\circ} \mathrm{C} / \mathrm{min}$ for $25 \mathrm{~min}$. Helium was used as carrier gas at a flow rate of $1 \mathrm{~mL} /$ 
$\min$ and detector/injector at a temperature of $260^{\circ} \mathrm{C}$. For identification of the peaks, the retention times of the fatty acid methyl ester (Supelco 37 Component FAME Mix) standards were compared with the observed peak retention times using the Openchrom software. Quantification was done by normalizing the peak area and expressed in percentage. The saturated and unsaturated percentages were compared by the Tukey test $(\mathrm{p}<0.05)$ using the online tool available at https://statpages.info.

\subsection{Oxidative stability}

Oxidative stability was expressed with the induction period in hours and was determined using 3 $\mathrm{g}$ of sample in a Rancimat apparatus (873 - Biodiesel Rancimat) at $110^{\circ} \mathrm{C}$ with airflow of $10 \mathrm{~L} / \mathrm{h}$ and 50 $\mathrm{mL}$ of distilled water in vials containing electrodes, according to the AOCS Cd 12b-92 method (AOCS, 1993). The oxidative stability indices were compared by the Tukey test $(\mathrm{p}<0.05)$ using the online tool available at https://statpages.info.

\subsection{Thermal behavior and solid fat content}

Previously established conditions (Márquez et al., 2013) were used with modifications. Samples were heated at $60{ }^{\circ} \mathrm{C}$ for $15 \mathrm{~min}$ and left at $4{ }^{\circ} \mathrm{C}$ for $24 \mathrm{~h}$. The thermograms of crystallization and melting were obtained using a Differential Scanning Calorimeter (DSC-60A - Shimadzu) coupled to the flow controller (FC-60A). The samples (5 mg) were placed in capped aluminum crucibles and cooled to $-50{ }^{\circ} \mathrm{C}$ at $10{ }^{\circ} \mathrm{C} /$ min, maintaining this temperature for $10 \mathrm{~min}$. The samples were then heated to $80^{\circ} \mathrm{C}$ at $5{ }^{\circ} \mathrm{C} / \mathrm{min}$ using a modulation amplitude of $1{ }^{\circ} \mathrm{C}$ every $60 \mathrm{~s}$.

The solid fat content (SFC) was determined based on the area percentages of the integrated melting thermogram at $10,15,20,25,30,35$, and $40 \mathrm{C}^{\circ}$ (Cobo et al., 2017; Gunstone et al., 1994). Measurements for onset, peak, and final temperatures for crystallization and melting, as well as enthalpies, were obtained using the SciDAVis program. The deconvolution peak and integration were determined using the MagicPlot software.

\subsection{Qualitative phase diagram}

Experimental phase diagrams were obtained by storing the samples in capped 5-ml glass tubes and kept inverted at temperatures of $10,11,12,13,14$,
$15,16,17,18,19$, and $20^{\circ} \mathrm{C}$ for 24 hours. The phase change described as solid, thick liquid, or liquid was visually evaluated. Non-flowing materials were named as solids, slowly-flowing materials were named as thick liquid, and immediately-flowing materials were named as liquids (Rocha et al., 2013).

\section{RESULTS AND DISCUSSION}

\subsection{Fractionation process}

The dry fractionation yielded $63.2 \%$ olein and $36.8 \%$ stearin, while the solvent fractionation yielded $71.8 \%$ olein and $28.2 \%$ stearin. In dry fractionation, crystals grew agglomerated on the vessel wall, unlike solvent fractionation, in which crystals grew dispersed in the medium. This higher amount of stearin in dry fractionation may be due to entrapment of the liquid fraction in the crystals. Slowly cooling at high temperatures typically results in larger crystals that can become trapped within the liquid fraction, while rapid cooling at low temperatures forms smaller crystals in larger quantities (Chaleepa et al., 2010; Rodrigues-Ract et al., 2010; Silva et al., 2008).

In solvent fractionation, there is a lower viscosity medium due to the presence of solvent and better heat transfer compared to the dry process, which results in a high nucleation rate and a rapid crystal growth which facilitate dispersion of the crystals. These effects were evaluated by Grall and Hartell (1992), who reported that the rate of nucleation and crystal growth increased when crystallization times decreased when using agitation. By increasing the agitation, the crystal mass increased, but with a greater effect on solid fractions at lower temperatures and less effect at elevated temperatures. Thus, with the use of solvents, crystals can grow more stable and faster than in the dry process, which could contribute to better phase separation (Kellens et al., 2007; Rossell, 1985).

\subsection{Fatty acid composition and oxidative stability}

Nine fatty acids were identified, including seven saturated (caproic; caprylic; capric; lauric; myristic; palmitic and stearic) one monounsaturated (oleic), and one polyunsaturated (linoleic) (Table 1). JKO had $73.4 \%$ saturated fatty acids and $26.6 \%$ unsaturated fatty acids, mainly lauric acid (37.4\%), myristic acid (10.0\%) and oleic acid (21.3\%), which 
Thermal and chemical characterization of fractions from Syagrus romanzoffiana kernel oil $\bullet 5$

TABLE 1. Fatty acid composition and oxidative stability of JKO and its fractions obtained by dry and solvent fractionation.

\begin{tabular}{|c|c|c|c|c|c|c|}
\hline \multicolumn{2}{|c|}{ Fatty acid } & \multirow{2}{*}{$\begin{array}{c}\text { JКО } \\
0.5 \pm 0.2\end{array}$} & \multirow{2}{*}{$\begin{array}{c}\text { Ed } \\
0.6 \pm 0.1\end{array}$} & \multirow{2}{*}{$\begin{array}{c}\text { Es } \\
1.2 \pm 0.1\end{array}$} & \multirow{2}{*}{$\begin{array}{c}\text { Od } \\
0.5 \pm 0.1\end{array}$} & \multirow{2}{*}{$\begin{array}{c}\text { Os } \\
0.7 \pm 0.1\end{array}$} \\
\hline Caproic & C6:0 & & & & & \\
\hline Caprylic & C8:0 & $9.1 \pm 0.1$ & $9.3 \pm 0.3$ & $9.8 \pm 0.3$ & $9.1 \pm 0.2$ & $9.3 \pm 0.4$ \\
\hline Capric & $\mathrm{C} 10: 0$ & $7.0 \pm 0.3$ & $7.2 \pm 0.3$ & $6.6 \pm 0.4$ & $7.0 \pm 0.2$ & $7.3 \pm 0.5$ \\
\hline Lauric & $\mathrm{C} 12: 0$ & $37.4 \pm 1.3$ & $39.0 \pm 0.5$ & $38.0 \pm 1.1$ & $37.2 \pm 1.1$ & $37.7 \pm 1.7$ \\
\hline Myristic & $\mathrm{C} 14: 0$ & $10.0 \pm 0.7$ & $10.0 \pm 0.3$ & $9.4 \pm 0.8$ & $9.8 \pm 1.1$ & $9.5 \pm 1.0$ \\
\hline Palmitic & $\mathrm{C} 16: 0$ & $7.8 \pm 1.0$ & $7.6 \pm 0.6$ & $7.6 \pm 0.6$ & $7.8 \pm 0.8$ & $7.2 \pm 0.5$ \\
\hline Stearic & C18:0 & $1.6 \pm 0.5$ & $1.7 \pm 0.4$ & $2.9 \pm 0.6$ & $1.7 \pm 0.3$ & $2.1 \pm 0.3$ \\
\hline Oleic & C18:1 & $21.3 \pm 1.1$ & $20.0 \pm 1.3$ & $20.0 \pm 0.9$ & $21.5 \pm 1.4$ & $20.4 \pm 1.6$ \\
\hline Linoleic & C18:2 & $5.3 \pm 0.7$ & $4.8 \pm 0.6$ & $4.5 \pm 0.6$ & $5.3 \pm 0.6$ & $4.8 \pm 0.6$ \\
\hline \multicolumn{2}{|c|}{$\Sigma$ Saturated } & $73.4 \pm 0.3$ & $73.3 \pm 0.1$ & $75.3 \pm 1.6$ & $75.4 \pm 1.2$ & $72.9 \pm 2.8$ \\
\hline \multicolumn{2}{|c|}{$\Sigma$ Unsaturated } & $26.6 \pm 0.4$ & $26.6 \pm 0.7$ & $24.8 \pm 1.6$ & $24.4 \pm 0.8$ & $26.8 \pm 1.1$ \\
\hline \multicolumn{2}{|c|}{ Oxidative stability (h) } & $19.4 \pm 1.1$ & $19.4 \pm 1.3$ & $22.0 \pm 1.2$ & $19.6 \pm 1.3$ & $17.3 \pm 1.5$ \\
\hline
\end{tabular}

JKO: Jerivá kernel oil, Ed: dry fractionation stearin, Es: solvent fractionation stearin, Od: dry fractionation olein, Os: solvent fractionation olein. The mean \pm standard deviation $(n=2)$.

is in agreement with what is reported in the literature (Coimbra and Jorge, 2011; Moreira et al., 2013).

In general, there was a slight numerical increase in saturated fatty acids in stearin (Es), with a consequent decrease in unsaturated ones, as opposed to olein (Os) fractions, although without statistically significant differences. Olein compositions were more similar to oil than stearins, which may indicate the presence of crystals in the oleins. However, it should be considered that the melting (or crystallizing) temperature of an oil or fat depends on the triacylglycerol (TAG) configuration, not just on the fatty acid composition. Previous work reported slight significant variations in the fatty acid compositions of coconut oil fractions (Marikkar et al., 2013) and palm oil fractions (Mo et al., 2016), but these fractions still had very distinct characteristics for the composition of TAG and thermal properties.

JKO presented oxidative stability of $19.4 \mathrm{~h}$, similar to that previously reported (Moreira et al., 2013). Despite the fact that stearins showed numerically greater oxidative stability than oleins, no statistically significant difference was found. In general, the oxidative stability of oils is related to their composition and distribution of the fatty acids in TAG, as well as the presence of constituents with antioxidant properties. As previously reported (Ullah et al., 2016), approximately $70 \%$ of the oxidative stability of chia oil fractions depended on the fatty acid profile, but $30 \%$ depended on antioxidant substances such as chlorogenic and caffeic acids, quercetin, and phenolic glycoside. Thus, the similarities in the fatty acid composition of the fractions may explain the similarities in their oxidative stabilities.

\subsection{Crystallization profile}

The analysis of DSC peaks serves to determine the transition temperature of a fat or oil (Tan and Che Man, 2002). The stearins obtained started and ended crystallization at higher temperatures than oleins (Table 2, Figure 2), i.e., stearins should be more abundant in high melting TAGs than oleins. The olein obtained from dry fractionation started crystallization before oil, presenting higher $\mathrm{T}_{\text {onset }}$. This may indicate that this olein dragged a reasonable amount of high melting (crystalline phase) TAGs into the liquid matrix during the fractionation process. Crystals are known to tend 
6•T.S. Tavares, K.T. Magalhães, N.D. Lorenzo and C.A. Nunes

TABLE 2. Crystallization and melting temperatures of JKO and its fractions obtained by dry and solvent fractionation.

\begin{tabular}{|c|c|c|c|c|c|c|c|}
\hline & \multicolumn{4}{|c|}{ Crystallization $\left({ }^{\circ} \mathrm{C}\right)$} & \multicolumn{3}{|c|}{ Melting $\left({ }^{\circ} \mathrm{C}\right)$} \\
\hline & $\mathbf{T}_{\text {onsetc }}$ & $\mathbf{T}_{\mathrm{pc} 1}$ & $\mathbf{T}_{\mathrm{pc} 2}$ & $\mathbf{T}_{\mathrm{fc}}$ & $\mathbf{T}_{\text {onsetm }}$ & $\mathbf{T}_{\mathrm{pm}}$ & $\mathbf{T}_{\mathrm{fm}}$ \\
\hline JKO & $15.8 \pm 0.3$ & $8.3 \pm 0.4$ & - & $-0.6 \pm 0.1$ & $17.2 \pm 0.9$ & $30.9 \pm 2.1$ & $36.0 \pm 1.9$ \\
\hline Ed & $16.3 \pm 0.9$ & $13.4 \pm 0.5$ & $6.4 \pm 0.4$ & $1.9 \pm 0.1$ & $16.4 \pm 0.8$ & $31.9 \pm 1.8$ & $36.6 \pm 1.8$ \\
\hline Es & $19.0 \pm 1.0$ & $16.7 \pm 0.8$ & $9.9 \pm 0.5$ & $1.0 \pm 0.0$ & $17.5 \pm 0.7$ & $33.4 \pm 1.2$ & $37.6 \pm 2.3$ \\
\hline Od & $16.1 \pm 0.8$ & $8.0 \pm 0.6$ & - & $0.1 \pm 0.0$ & $16.7 \pm 0.7$ & $30.3 \pm 2.0$ & $35.2 \pm 2.4$ \\
\hline Os & $14.5 \pm 0.8$ & $10.6 \pm 0.2$ & $3.4 \pm 0.2$ & $-2.1 \pm 0.2$ & $13.7 \pm 0.8$ & $30.1 \pm 1.5$ & $35.4 \pm 2.0$ \\
\hline
\end{tabular}

$\mathrm{T}_{\text {onsetc }}$ : crystallization onset temperature, $\mathrm{T}_{\mathrm{pc}}$ : crystallization peak temperature, $\mathrm{T}_{\mathrm{fc}}$ : final crystallization temperature, $\mathrm{T}_{\text {onsetm }}$ : melting onset temperature, $\mathrm{T}_{\mathrm{pm}}$ : melting peak temperature, $\mathrm{T}_{\mathrm{fm}}$ : melting final temperature. JKO: Jerivá kernel oil, Ed: dry fractionation stearin, Es: solvent fractionati $\mathrm{n}$ stearin, Od: dry fractionation olein, Os: solvent fractionation olein. The mean \pm standard deviation $(\mathrm{n}=2)$.

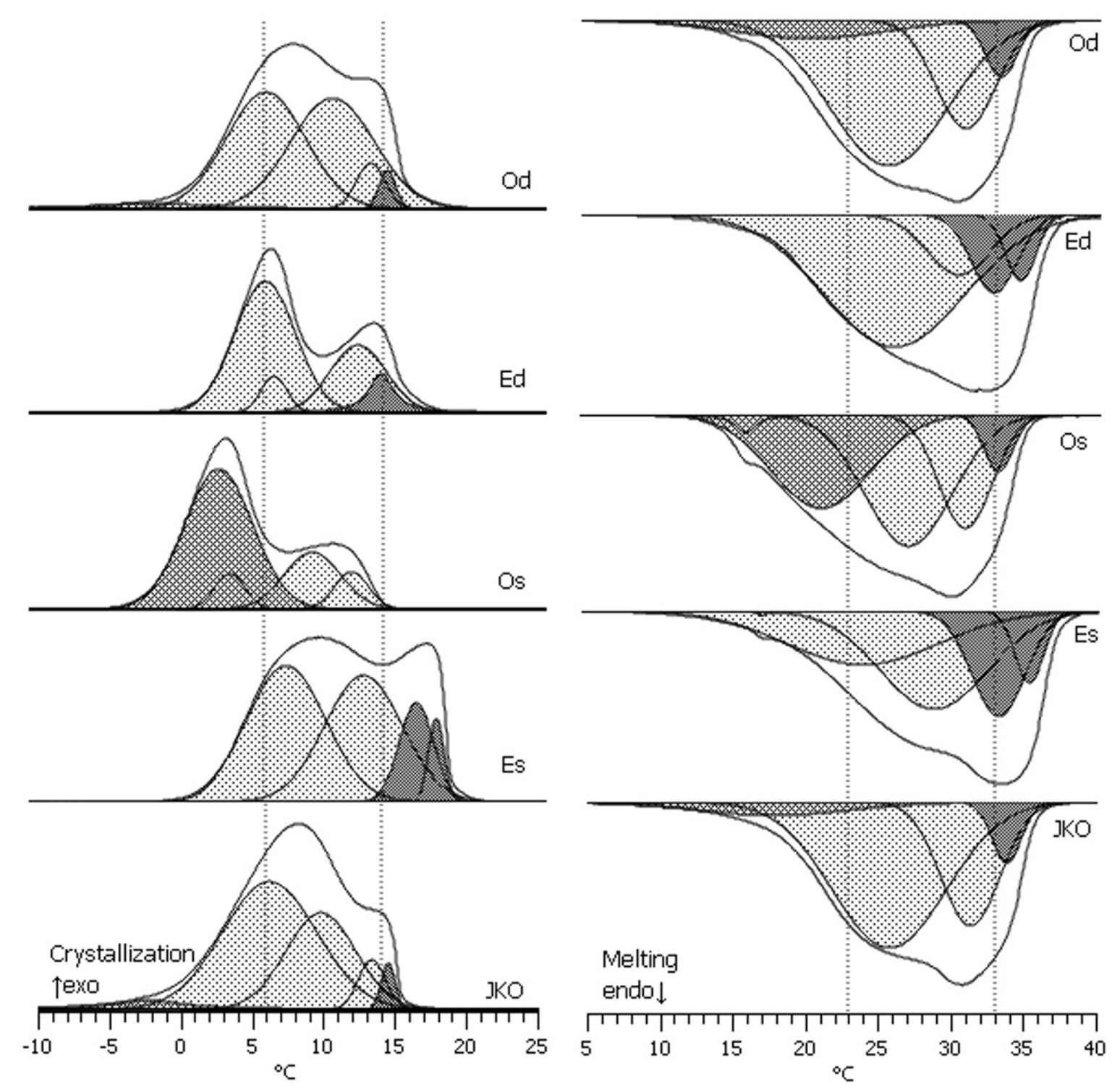

FIGURE 2. DSC crystallization and melting curves for JKO and its fractions obtained by dry and solvent fractionation. JKO: Jerivá kernel oil, Ed: dry fractionation stearin, Es: solvent fractionation stearin, Od: dry fractionation olein, Os: solvent fractionation olein. $\mathrm{n}=2$. 
to form clusters due to attractive interactions between them, which can drag the olein into the crystals, decreasing the efficiency of separation (Kellens et al., 2007). The largest crystals that can be observed during crystallization are often composed of small crystals held together by weak interactions. Thus, this agglomeration may lead to lower separation efficiency due to a high drag of liquid in the agglomerates.

The crystallization curves (Figure 2) presented different profiles in different temperature ranges. After deconvolution, the curves revealed some subevents associated with the crystallization of different TAG species. The thermograms were divided into three temperature ranges that were associated with the sub-events involving high, medium and low melting temperature TAGs. A first sub-event was associated with TAGs with crystallization temperature above 14 ${ }^{\circ} \mathrm{C}$; a second sub-event was associated with TAGs with crystallization temperatures between 6 and $14{ }^{\circ} \mathrm{C}$; and a third TAG-associated sub-event with crystallization temperatures below $6{ }^{\circ} \mathrm{C}$. The enthalpies associated with these sub-events were calculated and are presented in Table 3.

When the temperature was reduced and the JKO started to crystallize (Figure 2), a small crystallization peak was observed near $15{ }^{\circ} \mathrm{C}$ with $0.8 \mathrm{~J} / \mathrm{g}$ enthalpy (7.4\% total enthalpy) associated with high melting TAGs, overlapping the larger enthalpy of crystallization peaks of $9.5 \mathrm{~J} / \mathrm{g}$ (88\% total enthalpy) associated with medium melting TAGs (Table 3). This peak overlap, as well as the presence of a broad peak, is due to the crystallization of more than one TAG species in the same temperature range due to the complexity of the structures of these compounds. The sharpness of a DSC peak indicates the cooperative nature of the transition from TAG composition. If the transition occurs in a narrow temperature range, it is highly cooperative. Therefore, the crystallization (or melting) of two or more TAG structures could take place simultaneously in a certain temperature range, resulting in a broad or overlapping DSC peak (Tan and Che Man, 2002).

The olein crystallization curve from dry fractionation was similar to the JKO curve, but with slight differences in the enthalpies in each temperature range, i.e., a decrease in the enthalpy fraction associated with high melting TAGs $(0.2 \mathrm{~J} / \mathrm{g}$, $2.6 \%$ total enthalpy) and an increase associated to medium melting TAGs (7.3 J/g, 93.6\% total enthalpy) (Table 3). The crystallization olein peaks of the solvent fractionation occurred at lower temperatures compared to JKO and stearins. A relevant increase in enthalpy associated with low melting TAGs (5.5 $\mathrm{J} / \mathrm{g}, 70.5 \%$ total enthalpy) was also observed, as well as a decrease in enthalpy associated with medium melting TAGs $(2.3 \mathrm{~J} / \mathrm{g}, 29.5 \%$ total enthalpy) and absence of those with a high melting point (Table 3 ).

TABLE 3. Absolute and relative enthalpy for crystallization and melting of JKO and its fractions obtained by dry and solvent fractionation.

\begin{tabular}{|c|c|c|c|c|c|c|c|}
\hline & & & JKO & Ed & Es & Od & Os \\
\hline \multirow{6}{*}{ Crystallization } & \multirow{3}{*}{ Enthalpy $(\mathrm{J} / \mathrm{g})$} & $<6^{\circ} \mathrm{C}$ & $0.5 \pm 0.1$ & $0.0 \pm 0.0$ & $0.0 \pm 0.0$ & $0.3 \pm 0.0$ & $5.5 \pm 0.5$ \\
\hline & & $6-14{ }^{\circ} \mathrm{C}$ & $9.5 \pm 0.3$ & $4.0 \pm 0.4$ & $4.4 \pm 0.5$ & $7.3 \pm 0.4$ & $2.3 \pm 0.4$ \\
\hline & & $>14^{\circ} \mathrm{C}$ & $0.8 \pm 0.2$ & $0.5 \pm 0.1$ & $1.0 \pm 0.3$ & $0.2 \pm 0.1$ & $0.0 \pm 0.0$ \\
\hline & \multirow{3}{*}{ Enthalpy (\%) } & $<6^{\circ} \mathrm{C}$ & 4.6 & 0.0 & 0.0 & 3.8 & 70.5 \\
\hline & & $6-14{ }^{\circ} \mathrm{C}$ & 88.0 & 88.9 & 81.5 & 93.6 & 29.5 \\
\hline & & $>14^{\circ} \mathrm{C}$ & 7.4 & 11.1 & 18.5 & 2.6 & 0.0 \\
\hline \multirow{6}{*}{ Melting } & \multirow{3}{*}{ Enthalpy $(\mathrm{J} / \mathrm{g})$} & $<23{ }^{\circ} \mathrm{C}$ & $0.5 \pm 0.0$ & $0.0 \pm 0.0$ & $0.0 \pm 0.0$ & $0.8 \pm 0.2$ & $2.5 \pm 0.3$ \\
\hline & & $23-33{ }^{\circ} \mathrm{C}$ & $6.4 \pm 0.6$ & $5.5 \pm 0.6$ & $5.1 \pm 0.5$ & $6.5 \pm 0.4$ & $4.4 \pm 0.6$ \\
\hline & & $>33^{\circ} \mathrm{C}$ & $0.5 \pm 0.1$ & $1.4 \pm 0.3$ & $2.1 \pm 0.4$ & $0.5 \pm 0.1$ & $0.4 \pm 0.1$ \\
\hline & \multirow{3}{*}{ Enthalpy (\%) } & $<23{ }^{\circ} \mathrm{C}$ & 6.8 & 0.0 & 0.0 & 10.3 & 34.2 \\
\hline & & $23-33{ }^{\circ} \mathrm{C}$ & 86.5 & 79.7 & 70.8 & 83.3 & 60.3 \\
\hline & & $>33^{\circ} \mathrm{C}$ & 6.8 & 20.3 & 29.2 & 6.4 & 5.5 \\
\hline
\end{tabular}

JKO: Jerivá kernel oil, Ed: dry fractionation stearin, Es: solvent fractionation stearin, Od: dry fractionation olein, Os: solvent fractionation olein. The mean \pm standard deviation $(\mathrm{n}=2)$. 
The stearins began to crystallize at higher temperatures compared to oil and oleins, with an increase in the enthalpy fraction associated with high melting TAGs. A slighter variation was observed for dry fraction stearin, with a relative area of $11.1 \%(0.5 \mathrm{~J} / \mathrm{g})$ associated with high melting TAGs, while in solvent fractionation this variation was more relevant, yielding an $18.5 \%$ enthalpy stearin associated with high melting TAGs, as well as a decrease in the enthalpy fraction associated with medium melting TAGs (Table 3 ).

The solvent fractionation revealed a greater ability to modify the crystallization characteristics of JKO when compared to dry fractionation. Moreover, even with the similarity in fatty acid composition (Table 1), differences in oil thermograms and fractions were observed. This reinforces the notion that the thermal characteristics of the fractions depend not only on the fatty acid composition, but also on the disposition of these fatty acids in the TAGs, as well observed for the solvent fractionation of coconut oil (Sonwai et al., 2017).

\subsection{Melting profile}

The JKO melting process started at $17.2{ }^{\circ} \mathrm{C}$ $\left(\mathrm{T}_{\text {onset }}\right)$ and continued at $36.0{ }^{\circ} \mathrm{C}\left(\mathrm{T}_{\mathrm{f}}\right)$, with only one broad endothermic peak at $30.9^{\circ} \mathrm{C}$ (Table 2). The presence of only one endothermic transition can be characteristic of the constitution of the JKO, which should have TAGs with a less diversified structure when compared to other oils, such as palm oil, cocoa butter and some hydrogenated fats, which have fusion thermograms with a higher number of endothermic events (Tan and Che Man, 2002; Zaliha et al., 2004; Hinrichsen, 2016). The melting curve profile of the fractions was similar to that of oil, but with differences in initial, final and peak melt temperatures (Table 2). Similar results were found by Yantya et al. (2013).

After deconvolutions, the melting curves (Figure 2) also presented distinct sub-events which were divided into three temperature ranges associated with TAGs with different melting temperatures. In a first temperature range, low melting TAGs melted at temperatures below $23{ }^{\circ} \mathrm{C}$, predominantly in oleins; in a second range, medium melting TAGs melted at temperatures between approximately 23 and $33^{\circ} \mathrm{C}$; and in a temperature range above $33^{\circ} \mathrm{C}$, high melting TAGs were melted, predominantly in stearins. The enthalpies associated with these sub-events were calculated and are presented in Table 3.

All olein melting curves changed to lower temperatures compared to JKO (Figure 2); while stearin melting curves changed to higher temperatures. The main differences were related to the concentration of high melting TAGs in stearins and of low melting TAGs in oleins. This effect was most relevant in solvent fractionation, where enthalpy associated with the melting of high melting TAGs represented $29.2 \%$ of total enthalpy, compared to $20.3 \%$ in dry fraction stearin and $6.8 \%$ in JKO, similar to Macaúba kernel oil fractions (Magalhães et al., 2020a). In addition, fusion enthalpy associated with low melting TAGs represented $34.2 \%$ of total enthalpy in solvent fractionation olein, compared to $10.3 \%$ and $6.8 \%$ in dry fractionation olein and JKO, respectively.

\subsection{Solid fat content}

The SFC curves for the JKO and their fractions (Figure 3) revealed a substantial reduction in solid fat content with increasing temperature, especially in a narrow range between 25 and $35^{\circ} \mathrm{C}$, which should be the melting temperature range of the major TAGs of these products.

The SFC curves of the fractions showed that JKO's stearins and oleins had different melting profiles, despite similar fatty acid profiles (Table 1). It is known that TAGs can pack tightly together, which influences their melting. TAGs with larger amounts of unsaturated fatty acids cannot pack as tightly together because of kinks in the fatty acid chain, leading to a lower melting point. However, it has been reported that the SFC profile does not only depend on the level of saturation or unsaturation of fatty acids in the TAG. In a study on the thermal behavior of vegetable oils with changes in fatty acids in the TAGs, the authors observed that the solid contents tended to increase when saturated fatty acids were more symmetrically distributed between the external positions of the TAGs. They concluded that the physical properties of the oils studied depended on the fatty acid distribution in the TAGs, as well as on the composition of the fatty acids themselves (Bootello et al., 2016). Marikkar et al. (2013) and Mo et al. (2016) also reported distinct thermal properties for oleins and stearins from coconut oil and palm oil, even with slight variations in the fatty acid compositions of the fractions. 


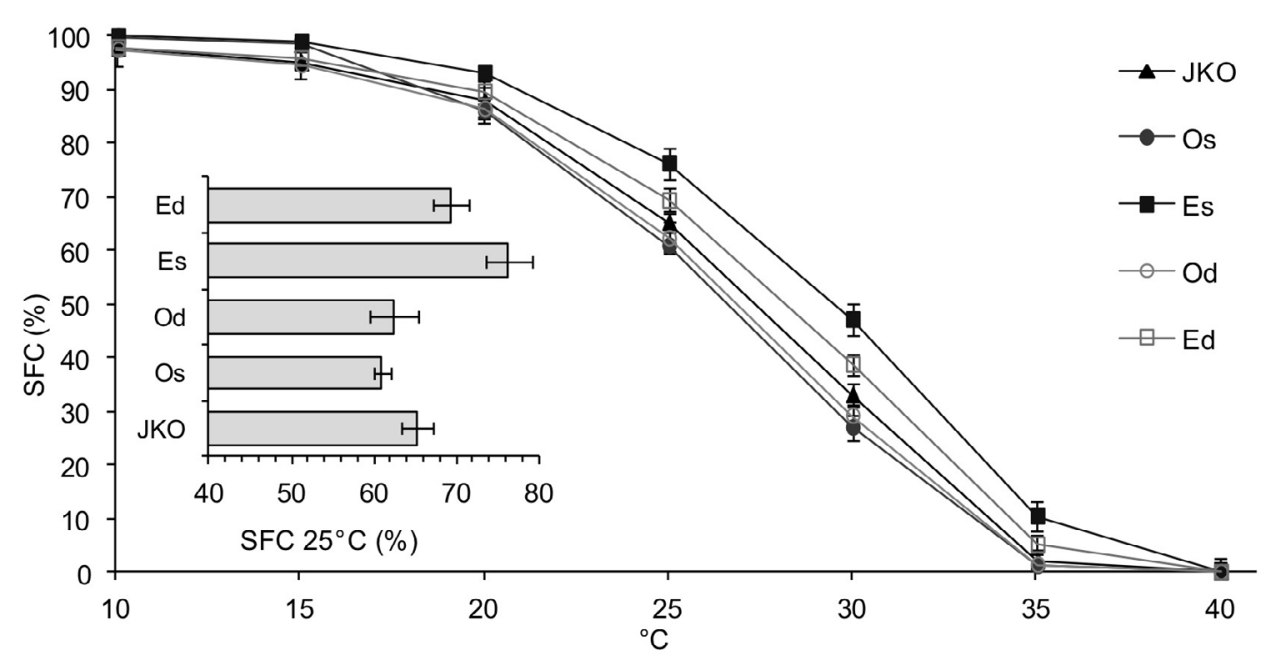

FIGURE 3. Solid Fat Content in JKO and its fractions obtained by dry and solvent fractionation. JKO: Jerivá kernel oil, Ed: dry fractionation stearin, Es: solvent fractionation stearin, Od: dry fractionation olein, Os: solvent fractionation olein. $\mathrm{n}=2$.

The oleins were completely melted at $35^{\circ} \mathrm{C}$, while stearins SFC were about $10 \%$ at this temperature. In most of the temperature ranges, oleins had lower SFC than JKO, while stearins had higher SFC, which was to be expected considering the enthalpy percentages associated with the lowest, medium and high melting TAGs previously presented (Table $3)$. This can be highlighted at the temperature of $25{ }^{\circ} \mathrm{C}$ (bars, Figure 3), especially for the solvent fractionation of stearin, which presented SFC above the other products throughout the temperature range, corroborating the enthalpy percentages associated with high and low melting TAGs (Table 3 ). The $\mathrm{SFC}$ at $25{ }^{\circ} \mathrm{C}$ of the solvent stearin was $17 \%$ higher than that of MKO, whereas the SFC at $25{ }^{\circ} \mathrm{C}$ of the solvent olein decreased by $7 \%$.

The increase and decrease in SFC is expected in the stearin and olein fractions, respectively, compared with JKO after fractional crystallization. It was reported that the SFC of stearins from a dry fractionation of palm oil was higher than that of the oil and melted completely above $45{ }^{\circ} \mathrm{C}$; while the SFC of oleins was lower than oil and entirely melted at $20{ }^{\circ} \mathrm{C}$ (Zaliha et al., 2004). This is because the olein fraction generally contains a higher content in low melting TAGs than oil and stearin.

The SFC curves of the fractions obtained in this work reveal that stearins and oleins have different profiles, making it possible to obtain fractions that cover varying ranges of solid fat as a function of temperature. With the increase in the solid fat content, the lipids tend to have a firmer texture, which is relevant to some applications in food formulation, mainly with higher contents close to $25^{\circ} \mathrm{C}$, which contributes to the fraction having greater resistance to melting in ambient conditions when compared to unfractionated oil (Sonwai et al., 2017).

\subsection{Qualitative phase diagram}

An experimental phase diagram (Figure 4) was obtained for the JKO and its fractions, where three phases were identified according to the visual appearance of the samples: solid, thick liquid and liquid. The phase diagram revealed that the stearins remained visually solid until higher temperatures (16 and $18{ }^{\circ} \mathrm{C}$ ) when compared to the oleins (13 to $15^{\circ} \mathrm{C}$ ). This behavior again corroborates the distribution of the lowest and highest melting TAGs in the fractions, as well as their solid fat content.

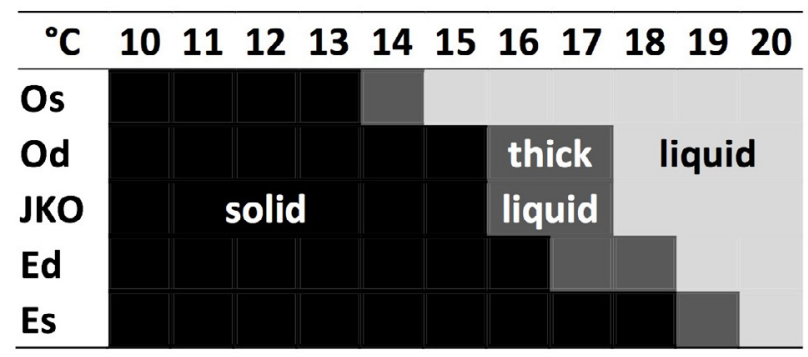

FIGURE 4. Experimental phase diagram of JKO and its fractions obtained by dry and solvent fractionation. JKO: Jerivá kernel oil, Ed: dry fractionation stearin, Es: solvent fractionation stearin, Od: dry fractionation olein, Os: solvent fractionation olein. $n=2$. 
The olein obtained from dry fractionation had a visual appearance similar to that of the oil, which is in agreement with the crystallization and melting thermal profiles obtained by DSC (Figures 2 and 3), indicating that the crystals may have dragged in the liquid phase. On the other hand, solvent fractionation resulted in more distinct fractions compared to JKO, with smaller liquid phase dragged in the clusters at the end of the fractionation, allowing for more effective separation and resulting in fractions with more distinct compositions. As reported by Kellens et al. (2007), the main advantage of solvent fractionation is the high separation efficiency and higher purity of the finished products. The solvent fractionation olein and stearin differed most from the oil in the phase diagram, with the olein visually solidified at $14{ }^{\circ} \mathrm{C}$ and the stearin at $18{ }^{\circ} \mathrm{C}$.

\section{CONCLUSIONS}

This work presented a new approach which showed that the thermal characteristics of Jerivá kernel oil can be modified by fractionation, but without statistically significant differences in fatty acid profile or oxidative stability. In general, stearins had higher crystallization and melting temperatures in addition to higher SFC, unlike oleins, which may be associated with the concentration of high melting TAGs in stearins. The type of fractionation (dry or solvent) influenced the chemical and thermal properties of Jerivá kernel oil fractions, and the solvent process promoted a more relevant differentiation of the fractions in relation to the oil. Thus, it was possible to obtain an olein with $7 \%$ less solid fat at $25^{\circ} \mathrm{C}$ which remained visually liquid at a temperature $2{ }^{\circ} \mathrm{C}$ below that of the oil, as well as a stearin with $17 \%$ more solid fat at $25{ }^{\circ} \mathrm{C}$ which remained visually solid at $3{ }^{\circ} \mathrm{C}$ above the oil. With these results, JKO oil can be an outstanding raw material and has the possibility of using its fractions, olein and stearin, in the food industry to produce spreads, specialty fats, ice cream, chocolate, and others products. These preliminary results may support future studies.

\section{ACKNOWLEDGMENTS}

The authors would like to thank the Central of Analysis and Chemical Prospecting of the Federal University of Lavras, Finep and Capes for supplying the equipment and technical support for experiments.
This study was supported by Conselho Nacional de Desenvolvimento Científico e Tecnológico (CNPq, Brazil) and Fundação de Amparo à Pesquisa de Minas Gerais (FAPEMIG, Brazil, APQ-00638-14 and PPM-00498-16).

\section{REFERENCES}

AOCS (1993). Official Methods and Recommended Practices of the American Oil Chemists Society. Champaing.

Bootello MA, Garcés R, Martínez-Force E, Salas JJ. 2016. Effect of the distribution of saturated fatty acids in the melting and crystallization profiles of high-oleic high-stearic oils. Grasas Aceites 67, e149. https://doi.org/10.3989/gya.0441161

Calliauw GH, Gibon V, De Greyt WFJ. 2007. Principles of palm olein fractionation: a bit of science behind the technology. Lipid Technol. 19, 152-155. https://doi.org/10.1002/lite.200700050

Chaleepa K, Szepes A, Ulrich J. 2010. Effect of additives on isothermal crystallization kinetics and physical characteristics of coconut oil. Chem. Phys. Lipids 163, 390-396. https://doi. org/10.1016/j.chemphyslip.2010.03.005

Cobo M, Deublein E, Haber A, Kwamen R, Nimbalkar M, Decker F. 2017. TD-NMR in Quality Control: Standard Applications, in Webb G (Ed.) Modern Magnetic Resonance. Springer, Cham, pp. 18191836. https://doi.org/10.1007/978-3-319-28388312.

Coimbra MC, Jorge N. 2011. Characterization of the Pulp and Kernel Oils from Syagrus oleracea, Syagrus romanzoffiana, and Acrocomia aculeata. J. Food Sci. 76, 1156-1161. https://doi. org/10.1111/j.1750-3841.2011.02358.x

Coimbra MC, Jorge N. 2012. Fatty acids and bioactive compounds of the pulps and kernels of Brazilian palm species, guariroba (Syagrus oleraces), jerivá (Syagrus romanzoffiana) and macaúba (Acrocomia aculeata). J. Sci. Food Agric. 92, 679-684. https:// doi.org/10.1002/jsfa.4630

Falasca SL, Miranda del Fresno C, Ulberich A. 2012. Possibilities for growing queen palm (Syagrus romanzoffiana) in Argentina as a biodiesel producer under semi-arid climate conditions. Int. J. Hydrogen Energy 37, 14843-14848. https:// doi.org/10.1016/j.ijhydene.2011.12.092

Gunstone FD. 2010. Lauric oils. Lipid Technol. 22, 168-168. https://doi.org/10.1002/lite.201000035 
Gunstone FD, Harwood JL, Padley FB. 1994. The Lipid Handbook. 2nd ed, CRC Press, London, UK.

Grall DS, Hartel RW. 1992. Kinetics of butterfat crystallization. J. Am. Oil Chem. Soc. 69 (8), 741-747. https://doi.org/10.1007/BF02635909

Hinrichsen N. 2016. Commercially available alternatives to palm oil. Lipid Technol. 28 (3), 6567. https://doi.org/10.1002/lite.201600018

Kellens M, Gibon V, Hendrix M, De Greyt W. 2007. Palm oil fractionation. Eur. J. Lipid Sci. Technol. 109, 336-349. https://doi.org/10.1002/ ejlt.200600309

Lescano CH, de Oliveira IP, Freitas de Lima F, Baldivia DS, Justi PN, Cardoso CAL, Raposo Júnior JL, Sanjinez-Argandoña EJ. 2018. Nutritional and chemical characterizations of fruits obtained from Syagrus romanzoffiana, Attalea dubia, Attalea phalerata and Mauritia flexuosa. J. Food Meas. Charact. 12, 1284-1294. https://doi.org/10.1007/s11694-018-9742-3

Magalhães KT, Tavares TS, Gomes TMC, Nunes CA. 2020b. Effect of process variables on the yield and quality of jeriva (Syagrus romanzoffiana) kernel oil from aqueous extraction. Grasas y Aceites 71, 339. https://doi.org/10.3989/gya.1063182

Magalhães KT, Tavares TS, Nunes CA. 2020a. The chemical, thermal and textural characterization of fractions from Macauba kernel oil. Food Res. Int. 130, 108925. https://doi.org/10.1016/j. foodres.2019.108925

Marikkar JMN, Saraf D, Dzulkifly MH. 2013. Effect of Fractional Crystallyzation on Composition and Thermal Behavior of Coconut Oil. Int. J. Food Prop. 16, 1284-1292. https://doi.org/10.1080/10 942912.2011.585728

Márquez AL, Pérez MP, Wagner JR. 2013. Solid fat content estimation by differential scanning calorimetry: Prior treatment and proposed correction. J. Am. Oil Chem. Soc. 90, 467-473. https://doi.org/10.1007/s11746-012-2190-z

Mo S-Y, Teng K-T, Nesaretnam K, Lai O-M. 2016. Similar physical characteristics but distinguishable sn-2 palmitic acid content and reduced solid fat content of chemically interesterified palm olein compared with native palm olein by dry fractionation: A lab-scale study. Eur. J. Lipid Sci. Technol. 118, 1389-1398. https://doi.org/10.1002/ejlt.201500305

Moreira MAC, Payret Arrúa ME, Antunes AC, Fiuza
TER, Costa BJ, Weirich Neto PH, Antunes SRM. 2013. Characterization of Syagrus romanzoffiana oil aiming at biodiesel production. Ind. Crops Prod. 48, 57-60. https://doi.org/10.1016/j. indcrop.2013.04.006

Pierezan L, Cabral MRP, Martins Neto D, Stropa JM, Oliveira, LCS, Scharf DR, Simionatto EL, Silva RCL, Simionatto E. 2015. Chemical composition and crystallization temperatures of esters obtained from four vegetable oils extracted from seeds of Brazilian cerrado plants. Quim. Nova 38, 328-332. https://doi.org/10.5935/01004042.20150018

Pittenger DR, James Downer A, Hodel DR, Mochizuki M. 2009. Estimating water needs of landscape palms in mediterranean climates. Horttechnology 19, 700-704. https://doi. org/10.21273/HORTSCI.19.4.700

Rocha JCB, Lopes JD, Mascarenhas MCN, Arallano DB, Guerreiro LMR, Cunha RL. 2013. Thermal and rheological properties of organogels formed by sugarcane or candelilla wax in soybean oil. Food Res. Int. 50, 318-323. https://doi. org/10.1016/j.foodres.2012.10.043

Rodrigues-Ract JN, Cotting LN, Poltronieri TP, Silva RC, Gioielli LA. 2010. Crystallization behavior of structured lipids by chemical interesterification of milkfat and sunflower oil. Food Sci. Technol. 30, 258-267. https://doi.org/10.1590/S010120612010000100038

Rossell JB. 1985. Fractionation of lauric oils. $J$. Am. Oil Chem. Soc. 62, 385-390. https://doi. org/10.1007/BF02541409

Silva RC da, Escobedo JP, Gioielli LA. 2008. Crystallization behavior of structured lipids by chemical interesterification of milkfat and sunflower oil. Quim. Nova 31, 330-335. https:// doi.org/10.1590/S0101-20612010000100038

Sonwai S, Rungprasertphol P, Nantipipat N, Tungvongcharoan S, Laiyangkoon N. 2017. Characterization of Coconut Oil Fractions Obtained from Solvent Fractionation Using Acetone. J. Oleo Sci. 66, 951-961. https://doi. org/10.5650/jos.ess 16224

Tan CP, Che Man YB. 2002. Differential scanning calorimetric analysis of palm oil, palm oil based products and coconut oil: effects of scanning rate variation. Food Chem. 76, 89-102. https://doi. org/10.1016/S0308-8146(01)00241-2 
Ullah R, Nadeem M, Ayaz M, Muhammad I, Muhammad T. 2016. Fractionation of chia oil for enrichment of omega 3 and 6 fatty acids and oxidative stability of fractions. Food Sci. Biotechnol. 25, 41-47. https://doi.org/10.1007/ s10068-016-0006-x

Yantya NAM, Marikkar JMN, Shuhaimia M. 2013. Effect of fractional crystallization on the composition and thermal properties of engkabang (Shorea macrophylla) seed fat and cocoa butter. Grasas Aceites 64 (5), 546-553. https://doi. org/10.3989/gya.023213

Zaliha O, Chong C, Cheow C, Norizzah AR, Kellens MJ. 2004. Crystallization properties of palm oil by dry fractionation. Food Chem. 86, 245-250. https://doi.org/10.1016/j.foodchem.2003.09.032 